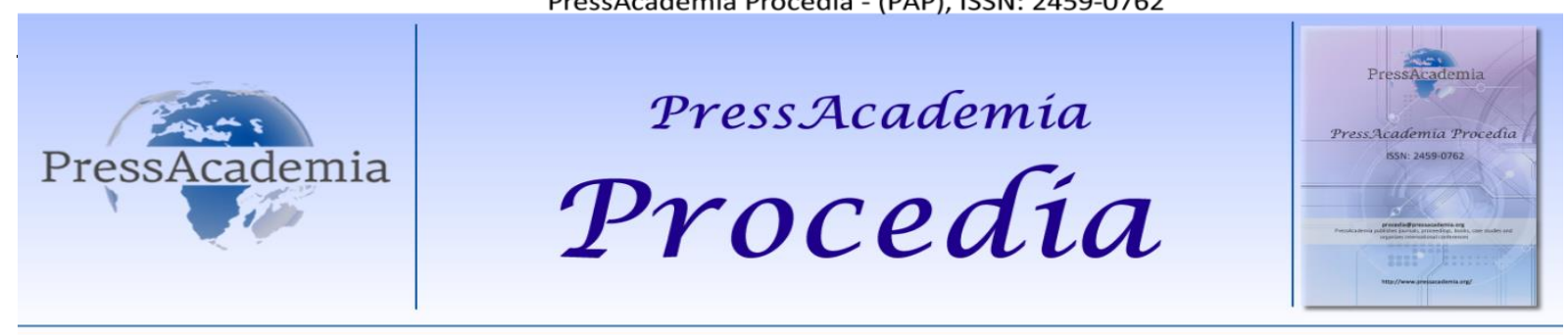

Istanbul Finance Congress (IFC), November 2-3, 2017, Istanbul, Turkey

\title{
IMPORTANCE OF REASONABLENESS TESTS AND RECOMMENDATIONS FOR ITS APPLICATIONS
}

\author{
DOI: 10.17261/Pressacademia.2017.743 \\ PAP-IFC- V.6-2017(7)-p.39-42
}

\author{
Huseyin Mert ${ }^{1}$, Ece Bas ${ }^{2}$, Hasan Melih Eren $^{3}$ \\ ${ }^{1}$ Okan University, Department of Accounting and Auditing, Istanbul Turkey. huseyin.mert@okan.edu.tr \\ ${ }^{2}$ Okan University, Institute of Social Sciences, Istanbul, Turkey. ecebs@hotmail.com \\ ${ }^{3}$ Okan University, Institute of Social Sciences, Istanbul, Turkey. erenhasa@yahoo.com
}

\section{To cite this document}

Mert, H., Bas, E., Eren, H.M., (2017). Imporrtance of reasonableness tests and recommendadtions for its applications. PressAcademia Procedia (PAP), V.6..,p.39-42.

Permanant link to this document: $\underline{\text { http://doi.org/10.17261/Pressacademia.2017.743 }}$

Copyright: Published by PressAcademia and limited licenced re-use rights only.

\begin{abstract}
Objective- Analytical procedures have higher potential compared to test of details in terms of analysing the account relationships, detecting significant risk of misstatement, reducing audit fieldwork and testing management assertions. In order to get benefit of those procedures, auditors should access more entity specific resources and invest more time in planning the audit program. In this study, reasonableness tests that are generally used in substantive analytical procedures are analysed through industry examples and their role in reducing the audit risk is demonstrated.

Methodology- In this study, case study method is used as a research methodology. The reason of selecting this methodology is due to its relevance in accordance with the objective of the study as well as providing an opportunity to auditors that would like to implement reasonableness tests.

Findings- This study reveals, through examples that can be used in practice, that the management claims can be tested more soundly through rationality tests when more time is given to the stages of understanding the enterprise and planning the audit.

Conclusion- Among the analytical review techniques, reasonableness test is highly effective technique for testing the relationship between non-financial information and financial information. In order to use the reasonableness tests more frequently in the evidence collection, understanding the enterprise, more senior and industry specific team construction and accessing the non-financial information by inquiring also the performance indicators used by the enterprise are important. Agreements for longer than a year between the auditor and the company will reinforce the auditor's accumulated knowledge on the enterprise that will increase number of reasonableness tests.
\end{abstract}

Keywords: Reasonableness Test, analytical procedures, independent audit, analytical review, risk of misstatement

JEL Codes: M40, M41, M42

\section{USSALLIK TESTLERININ ÖNEMI VE UYGULANMASINA YÖNELIK ÇÖZÜM ÖNERILERi}

\section{ÖZET}

Amaç- Analitik inceleme prosedürleri, hesaplar arasında iletişim kurma, önemli yanlışlık riskleri ile ilgili bilgi verme, denetim süresini verimli kullanma ve yönetim iddialarını doğrulama açısından detay testlere göre daha fazla kanıt sunma potansiyeline sahiptir. Öte yandan, bu prosedürlerin kanıt toplama aşamasında kullanılması için denetçinin işletme içi kaynaklara ulaşması ve iyi bir denetim programı planlaması yapması gereklidir. Bu çalışmada, özellikle analitik inceleme türlerinden kanıt toplama aşamasında kullanılan ussallık testlerine değinilmiş ve örnekler vasıtasıyla nasıl etkin kullanılabileceği ve denetim riskini nasıl azaltabileceği gösterilmeye çalışılmıştır.

Yöntem- Söz konusu çalışmada araştırma yöntemi olarak örnek olay yöntemi kullanılmıştır. Bu yöntemin seçilmesinin en temel nedeni, yöntemin çalışmanın amacıyla uygun olması ve ussalık testlerini uygulamak isteyen kullanıcılara yön gösterebilmesidir.

Bulgular- Çalışmada, uygulamada kullanılabilecek örnekler üzerinden gidilerek işletmeyi anlama ve denetim planlama aşamalarına daha fazla zaman ayrıldı̆̆ı takdirde, yönetim iddialarının ussallık testleri ile daha güçlü test edilebildiği ortaya konmuştur.

Sonuç- Analitik inceleme türleri içerisinde, ussallık testleri özellikle finansal olmayan bilgilerin finansal bilgilerle bağlantısını test etmesi açısından son derece etkin bir teknik olarak göze çarpmaktadır. Ussallık testlerinin kanıt toplamada daha etkin kullanılabilmesi için işletmeyi anlama süreci, kıdemli denetçilerin kullanılması, denetçinin sektör tecrübesi ve denetçilerin özellikle iç kontrol testleri esnasında işletmenin kullandığı performans göstergelerini de sorgulayarak finansal olmayan bilgilere erişmeye çalışmaları faydalı olacaktır. Ayrıca, denetçi ile 
işletmenin bir yıldan uzun süreli anlaşma yapması, denetçinin işletme ile ilgili birikimli bilgisini kuvvetlendirecek ve denetçinin ussallık testlerine daha fazla yatırım yapmasını sağlayacaktır.

Anahtar Kelimeler: Analitik inceleme prosedürleri, finansal tablo, bağımsız denetim, analitik inceleme, önemli yanlışlık riski.

JEL Kodları: M40, M41, M42

\section{GiRiş}

Denetim planlaması ve tamamlanması aşamasında analitik inceleme prosedürlerinin kullanılması Uluslararası Denetim Standartları uyarınca zorunlu tutulmaktadır. Analitik inceleme prosedürlerinin kullanılabileceği diğer bir alan denetimin yürütülmesi esnasında kanıt toplama dönemidir. Denetim riskinin düşürülmesi, yönetim iddiaları ile ilgili daha kaliteli kanıtın toplanması, diğer hesap kalemlerini etkileyebilecek kanıtlara ulaşıması ve denetim süresinin kısaltılması açısından kanıt toplama aşamasında analitik inceleme prosedürlerinin kullanılması son derece faydalıdır.

Analitik inceleme türleri içerisinde, ussallık testleri özellikle finansal olmayan bilgilerin finansal bilgilerle bağlantısını test etmesi açısından son derece etkin bir teknik olarak göze çarpmaktadır. Yapısı itibarıyla, ağırlıklı olarak kanıt toplamada kullanılabilecek bu teknik, işletme içi kaynaklara erişim gerektirmesi, işletmenin süreçlerinin ve iş sahasının iyi anlaşılmasını gerekli kılması ve akıl yürütme açısından mesleki deneyim ve tecrübe gerektirmesi açısından özellikle dizayn aşamasında zaman yatırımı gerektiren, ancak doğru dizayn edildikten sonra denetime etkinlik ve verimlilik katan bir inceleme türüdür.

\section{LITERATÜR INCELEMESI}

Analitik inceleme prosedürlerine dönük literatürde oldukça fazla çalışma olmasına karşın bu konunun denetimin yürütülmesi özelinde incelendiği çalışmalar sınırlıdır.

Mckee (1989) tarafından yapılan çalışma ile muhasebe denetiminin zaman içinde gösterdiği değişim ve meslekte yaşanan gelişmeler, işletmelerin finansal tablolarının doğruluk ve güvenilirliğini araştırırken incelenen finansal tablolar üzerinde etkili olabileceği düşünülen ancak daha önce denetim çalışmalarında ele alınmamış işletmeye ait finansal ya da finansal olmayan birçok bilginin de dikkate alınmasını zorunlu kılmıştır. Bu zorunluluğun ortaya çıkması, muhasebe denetiminde "analitik inceleme prosedürleri" ni gündeme getirmiştir.

KGK tarafından yapılan çalışmalarda ise, finansal tablolardaki hesaplar başta olmak üzere işletmeye ait tüm verilerin karşılaştırılması ve aralarındaki ilişkinin araştırılmasının analitik inceleme kavramının bir sonucu olduğu görülmektedir. Buna ilaveten analitik inceleme yoluyla aralarında anlamlı ilişkilerin var olduğu kabul edilen bilgilerin doğrulanmış ve bunlar arasında olağan kabul edilemeyecek sapmaların ortaya çıkarabileceği tespit edilmiştir. Ayrıca, denetçi analitik inceleme tekniklerini temel bağımsız denetim tekniği olarak uyguladığında; analitik inceleme tekniklerinin uygunluğu, hesaplamalarda kullanılan verilerin güvenilirliği, beklenen sonuçların güvenilirliği ve ortaya çıkan farkların değerlendirilmesi hususları da önem arz etmektedir.

Analitik inceleme prosedürlerinin tanımı AICPA (American Instıtute of Cerficated Public Accountant-Amerikan Sertifikalı Kamu Muhasebecileri Kurumu) tarafından 1988 yılında yayınlanan SAS No:56 "Analitik Prosedürler" yönetmeliğinde şu şekilde yapılmıştır; "çeşitli finansal ve finansal olmayan veriler ile işletmenin kayıtları arasındaki anlamlı ilişkilerin incelenmesiyle elde edilen bilgilerin, denetçi tarafından geliştirilen beklentilere uyup uymadığına bakılması işlemlerine analitik inceleme prosedürleri adı verilmektedir" (AICPA, 1989). IFAC (International Federation of Accountants) tarafından yayınlanan UDS 520 Analitik Prosedürler'de ise; "finansal ve finansal olmayan veriler arasındaki ilişkilerin makullüğünü araştıran çalışmalardan elde edilen finansal verilerin değerlendirilmesi ve olağandışı dalgalanmaların, tutarsız ilişkilerin ve tahmin edilen tutarlardan sapmaların karşılaştırılmasıdır" şeklinde bir tanımlama yapılmıştır (IFAC, 2007).

Kaval'ın (2005) yapmış olduğu çalışmalarda denetimin rutin, şekli hesap denetiminden çıkıp, risk ağılıklı denetime kayma sürecinde analitik incelemelerin değerinin de arttığı savunulmaktadır. Analitik inceleme teknikleri uygulanırken elde edilen sonuçlar işletmenin önceki dönemlerine ait verileriyle, aynı sektörde faaliyet gösteren benzer işletmelerin verileriyle, sektör ortalamalarıyla, işletmenin bütçelediği rakamlarla, işletmenin ve denetçinin beklentileriyle karşılaştırılmasının da mümkün olduğu Arens vd. (2012) tarafından yapılan çalışmada ele alınmıştır.

Blocher ve Patterson (1996) çalışmalarında, trend analizleri, oran analizleri, ve modele dayalı prosedürler olmak üzere üç tür analitik inceleme tekniğinden bahsetmektedirler. Fraser vd. (1997) ise çalışmalarında analitik inceleme tekniklerine biraz daha geniş bir bakış açısı getirmişlerdir ve bu teknikleri, gözden geçirme gibi nicel olmayan veya yargısal teknikler; trend analizi, oran analizi ve ussallık testleri gibi basit kantitatif teknikler; regresyon analizi gibi ileri kantitatif teknikler olarak sınıflamışlardır.

Analitik inceleme tekniklerinin sık kullanılması gereken alanlardan biri, denetimin yürütülmesi, yani kanıt toplama aşamasıdır. Bu aşamada kullanılabilecek teknikler, işletme verileri ile sektör verilerinin karşılaştırılması, işletme cari dönem verileri ile önceki dönemlere ait aynı verilerin karşılaştırılması, işletme verileri ile işletme tarafından belirlenmiş beklenen sonuçların karşılaştırılması, işletme verileri ile denetçi tarafından belirlenmiş beklenen sonuçların karşılaştırılması ve son olarak işletme verileri ile finansal olmayan verilerin ortaya koyduğu beklenen sonuçların karşılaştırılması şeklinde sıralanabilir. İşletme verileri ile finansal olmayan verilerin ortaya koyduğu sonuçların karşılaştırılması tekniğinde ussallık testleri kullanılabilir. Ussallık testleri, trend ve rasyo analizlerine göre daha az toplulaştırılmış veri kullandığından diğer testlere oranla daha fazla kesinlik sağlayabilir. Denetçinin daha yüksek düzeyde denetim kanıtına ihtiyacı bulunması durumunda ussallık testlerini, diğer testlere tercih etmesi beklenebilir. 
Kanıt toplama aşamasında kullanılan ussallık testleri 4 ana süreçten ibaret olup, denetçinin bu süreçleri takip etmesi tekniğin doğru uygulanması açısından son derece önemlidir: Bağımsız bir beklenti oluşturma, denetçinin test edeceği kalemle ilgili bir önemlilik eşiği belirlemesi, farkın hesaplanması, çıkan farkların sorgulanması ve testin sonucunun belirlenmesi. Ussallık testlerinin başarılı olabilmesi için uygulama esnasında kesinliği etkileyen dört faktör bulunmaktadır: Verinin parçalara ayrılmış olması, Verinin güvenilirliği, Tahmin etme yetkisi, Analitik inceleme tekniği.

Adnan Dönmez ve Ayten Ersoy (2011), Sermaye Piyasası Kurulu tarafından yetkilendirilen denetim şirketleri üzerinden yaptıkları araştırmada en çok kullanılan analitik inceleme türünün cari dönem verileri ile önceki dönem verilerini karşılaştırmak olduğunu, en az kullanılan türün ise finansal olmayan verilerin ortaya koyduğu beklenen sonuçların karşılaştırılması olduğu sonucuna ulaşmışlardır. Aynı araştırmada, ussallık testlerinin de analitik incelemede yararlanılan teknikler içerisinde diğerlerine oranla daha az kullanılan bir yöntem olduğu sonucuna varılmıştır. Bunun sebebi incelendiğinde, finansal olmayan veriler ile finansal veriler arasındaki ilişkinin kurulabilmesi için denetim ekibinin işletmeyi, çevresini ve süreçleri anlamak için zamana ihtiyacı olması, mesleki yargı ve deneyim gerektirmesi ve çoğu zaman finansal olmayan verilerin işletmeden temin edilebilmesinde zorluk yaşanması göze çarpmaktadır.

\section{VERI, YÖNTEM, BULGULAR, ANALIZ}

Çalışmada, örnek vaka yöntemi kullanılarak ussallık testlerinin daha fazla denetim kanıtı sağladığı ve nasıl verimli kullanılabileceği gösterilmiştir. Kullanılan örnek vaka yönteminde, üretim sektöründen bir şirket ele alınmış ve kar veya zarar tablosundaki en önemli gelir kaynağı olan hasılat kalemi test edilmiştir.

İşletme, A ürününü üretmiş ve ürünün satış miktarı 2017 senesinde 20 adet olarak gerçekleşmiştir. İşletme yönetimi, 2016 Aralık ayında uygulanan fiyatlarına 2017 senesinde yüzde 10 zam yaptığını beyan etmiştir. 2016 Aralık ayındaki fiyatlar Satış Sisteminden alınmış ve satış fiyatı 100 TL olarak belirlenmiştir.

Denetçi, işletmenin içinde bulunduğu pazarı anlamaya çalışmış ve sektör raporlarından geçen sene ile karşılaştırıldığında pazar büyümesinin yüzde 10 civarında olduğunu görmüştür. Öncelikle gerçekleşen miktarların doğruluğunu sorgulayan denetçi, geçen seneki satış miktarları ile bu seneki satış miktarları arasında yüzde 7 civarında bir artış olduğunu fark etmiştir. Beklentisini pazar büyümesi kadar miktar artışı olarak belirleyen, yanılma eşiğini de en fazla yüzde 1 olarak kabul eden denetçi, aradaki yüzde 2'lik farkın sebebini sorgulama gereği duymuştur. Satış ve pazarlama müdürü ile yapılan görüşmede, pazar kaybının sebebi sektöre yeni giren B şirketinin agresif fiyat politikası ile pazardan pay alması olarak yorumlanmıştır. Dış kaynaklardan yapılan araştırmada, B şirketinin gerçekten 2017 senesinde pazara girdiği ve agresif büyüme hedefini kamuoyu ile paylaştığı doğrulanmıştır. Denetçi, bu bulgular ışığında pazar kaybını makul bulmuş ve testin ikinci aşamasına ilerlemiştir.

İ̧̧letme yönetiminin yaptığı yüzde 10 'luk artış beyanı, işletmenin içerisinde bulunduğu sektördeki enflasyon oranı ile karşılaştırılmış ve fiyatların yüzde 10 civarında arttığı bulunmuştur. Bu durumda denetçinin yüzde 10 artış beklentisi ile işletmenin beyanı örtüşmektedir. Denetçi makul bulduğu bu artış oranını ussallık testinde kullanmaya karar vermiştir.

Gerçekleştirilen ussallık testinde, denetçinin beklentisi "Satış miktarı * 2016 Aralık satış fiyatı * (1+\%10)" denkleminin ciro hesabında gözüken bakiyeyi doğrulamasıdır. Denetim esnasında kullanılan önemlilik seviyesi dikkate alındığında ve satış süreci ile önemli yanlışlık riski değerlendirildiğinde denetçi yüzde $3^{\prime} l u ̈ k$ bir fark eşiğini makul olarak değerlendirmektedir. Hesaplama sonucunda beklenen ciro $20 * 100 *(1,1)=220$ TL bulunmuştur. Mizanda gözüken satış bakiyesi ise 200 TL'dir. Aradaki fark 20 TL olup, test edilen ciro bakiyesinin yüzde 10'una denk gelmektedir. Bu durumda, denetçi varsayımlarını tekrar gözden geçirmiştir. İşletme yönetimi ile yapılan görüşmede B şirketinin pazara girişi esnasında, pazar paylarını korumak için iki ayda satış kanalına yüzde 10 iskonto verdikleri öğrenilmiştir. Bu iskontolar satış sisteminde sorgulanmış ve tutarının 16 TL olduğu tespit edilmiştir. Denetçi, beklenen ciro tutarını 204 TL olarak revize etmiş ve yeni oluşan farkın ciroya oranı yüzde 2 çıktığından belirlediği fark eşiğinin altında kalmasından hareketle yeterli denetim kanıtının toplandığı sonucuna varmıştır.

Örnek vaka analiz edildiğinde detaylı testlere göre yönetim iddialarının daha güçlü test edildiği gözlenmektedir. Detaylı testlerde şirketin kestiği faturalara bakılarak yönetim iddialarından gerçekleşme ve doğruluk test edilebilirken, ussallık testleri ile gerçekleşme, doğruluk ve tamlık iddialarının test edildiği ve denetim riskinin azaltıldığı görülmektedir. Aynı zamanda ussalık testleri vasıtasıyla fatura testinde harcanan zamana kıyasla daha az zaman harcanmış olup denetim sürecinin verimliliği de sağlanmış olmaktadır.

\section{SONUÇ, TARTIŞMA}

Bu çalışmada, analitik inceleme tekniklerinden ussallık testi ele alınmış ve uygulama safhasında dikkat edilmesi gereken hususlara değinilmiştir. Bunlar sırasıyla, tahmin edebilme yetisi yüksek olan finansal veya finansal olmayan bilgiye ulaşmak, bu bilgiyi diğer kaynaklardan doğrulamak, bağımsız bir beklenti oluşturmak, beklenti ile test edilen kalem arasında oluşabilecek maksimum fark eşiğini önemlilik ve önemli yanlışlık riski değerlendirmeleri ışı̆ında belirlemek ve çıkan sonuç fark eşiğini aşıyorsa farkın sebebini doğurabilecek dikkate alınmayan verileri gözden geçirmektir.

Ussallık testleri, doğası itibarıyla kanıt toplama aşamasında kullanılan bir analitik inceleme tekniğidir. Testin dizayn edilmesi zaman alsa bile, testin sonuçları yönetim iddiaları ile denetim riskini azaltıcı kanıtlar toplanmasında denetçiye önemli ölçüde katkıda bulunmaktadır.

SPK tarafından bağımsız denetim lisansı almış denetim şirketleri üzerinden yapılan araştırmalarda ussallık testinin ve finansal olmayan bilgilerin kanıt toplama aşamasında az kullanıldığı ortaya konmuştur. Bu araştırmalardan hareketle denetçilerin yönetim iddialarını daha etkin bir şekilde test edecek bir tekniği kullanmaktan kaçındıkları, denetim riskini arttırdıkları ve detay testlere daha fazla zaman ayırarak denetim sürecini verimsiz kıldıkları sonucuna ulaşılabilir.

Ussallık testlerinin kanıt toplamada daha fazla kullanılabilmesi için işletmeyi anlama süreçlerine daha fazla zaman ayrılması, testlerin dizayn aşamasında daha kıdemli denetçilerin kullanılması, denetim ekibine seçilecek denetçilerin işletmenin içinde bulunduğu sektörde deneyimli 
olmasına dikkat edilmesi ve özellikle iç kontrol testleri esnasında işletmenin kullandığı performans göstergelerini de sorgulayarak finansal olmayan bilgilere erişmeye çalışmaları faydalı olacaktır. Ayrıca, denetçinin işletmeyi tanıma sürecinin bu testlerin kullanımını arttıracağından hareketle denetçi ile işletmenin bir yıldan uzun süreli anlaşma yapması, denetçinin işletme ile ilgili birikimli bilgisini kuvvetlendirecek ve denetçinin ussallık testlerine daha fazla yatırım yapmasını sağlayacaktır.

Son olarak, ussallık testlerinin iyi belgelendirilmesi ve anlaşılabilirliğinin yüksek olması, bir sonraki dönem denetime gelen ekibin finansal olmayan bilgilerin nasıl temin edileceği ve finansal tablolarla bağlantııının nasıl kurulacağı konularında işini kolaylaştıracaktır. Bu açıdan, denetimin her safhasında önem arz eden çalışma kă̆ıtlarının düzenli tutulması, ussallık testlerinin uygulama sonuçlarının belgelendirmesinde daha da önem arz etmektedir.

\section{KAYNAKLAR}

McKee T., Modern Analytical Auditing: Practical Guidance for Auditors and Accountants, Quorum Boks, New York, 1989, SS. 5

KGK, http://www.kgk.sakarya.edu.tr/FileUploads/Src/de3a13f5-3322-4362-a3b788cfe3e2e3e0/B\%C3\%B6I\%C3\%BCm\%203 2\%20ekitap\%20-\%204.6.\%20Analitik\%20Prosed\%C3\%BCrler.pdf, Erişim Tarihi: 24.05.2017

Kaval H., 2005, Muhasebe Denetimi, Gazi Kitabevi, Ankara, ss. 146

Choo T.M., Chua M.K., Ong C.B., Tan T.H., ,1997, “Analytical Procedures for New and Matured Industries”, Managerial Auditing Journal, $12 / 3,123-134$

Arens A.A., Elder R.J., Beasley M.S., 2012, Auditing and Assurance Services an Integrated Approach, Fourteenth Edition, Pearson,ss. 224.

AICPA, Statements on Auditing Standarts No:56 Analytical Procedures, New York, 1989.

IFAC, International Standarts on Auditing 520: Analytical Procedures, Handbook of International Auditing, Assurence and Ethics Pronouncements, New York, 2007.

Blocher E., Patterson G.F., "The Use of Analytical Procedures”, Journal of Accountancy, February (1996), 53-55.

Fraser I.A.M., Hatherly D.J., Lin K.Z., "An Empirical Investigation of The Use of Analytical Review By External Auditors", British Accounting Review, 29, (1997), 35-47.

Ameen E.C., Strawser J.R., "Investigating The Use of Analytical Procedures: An Update and Extension", Auditing: A Journal of Practice and Theory, Vol.13, No.2, (1994), 69-76.

Dönmez A., Ersoy A., “Bağımsız Denetim Sürecinde Analitik İnceleme Prosedürleri: Türkiye'de SPK'dan Yetki Almış Denetim Firmaları Üzerine Bir Araştırma”, Bilig, 56, (2011), 131-132 